\title{
Secular trends in growth
}

\author{
T. J. Cole \\ Department of Epidemiology and Public Health, Institute of Child Health, 30 Guilford Street, London WC1N 1EH, UK
}

\begin{abstract}
Since the 19th century there have been clearly documented secular trends to increasing adult height in most European countries, with current rates of $10-30 \mathrm{~mm} /$ decade. Over the same period menarcheal age has also fallen steeply, but has now stabilized at approximately 13 years and may be rising again. Height trends tend to be greater in childhood than in adulthood due to the associated advance in maturation, but no trends are apparent before the age of 2 years. In particular, birth-weight trends are small and different in shape from height trends. The adult height trend matches that at age 2 years, so that the increment in adult height has already been achieved by age 2 years. To try to identify factors relating to the secular trend, increased height gain in late infancy is hypothesized to be equivalent to a reduction in stunting, and stunting is thought to be caused by impaired growth in the long bones of the leg in later infancy. Leg growth may be regulated by the expression of growth-hormone receptors on the growth plates, which it is hypothesized are susceptible to the interaction between concurrent nutrition and the nominal growth rate set during pregnancy. The timing of menarche is also likely to be determined by some growth factor operating near the time of birth, which also affects later weight, but not height.
\end{abstract}

\section{Secular trend: Growth: Height: Age at menarche}

Tall stature has always been a sign of status and privilege. The association between the two is so strong that it is enshrined in the English language, for example, take the phrase 'a woman of stature'. This etymological evidence hints not only at the duration and intensity of the link, but also at the mechanisms underlying the secular changes that have taken place in height over the centuries. It suggests that not only is tall stature associated with good living, it is also a direct result of it.

The phrase 'secular trend' is used more widely than 'secular change', implying change in one particular direction, a trend to continually increasing height over time. Yet this trend to increasing height is often not what happens. Within recent history human height has gone down as well as up, and even on the scale of millennia height has been seen to fall. In Latin America 8000 years ago mean height was greater than it is now, $70 \mathrm{~mm}$ above its most recent nadir in 1940 (Bogin \& Keep, 1999). At the beginning of the 19th century height fell in several European countries, linked to the effects of the industrial revolution (Floud et al. 1990). At the other temporal extreme, variations in stature attributable to the season of the year can also be considered a form of secular change. Weber et al. (1998) detected a seasonal trend in the height of 507000 18-year-old Austrian conscripts related to their month of birth, with a peak-totrough amplitude of $6 \mathrm{~mm}$ peaking in April. Despite the differences in time scale of these examples, they are likely to reflect to some degree the same underlying causes.

The aim of the present paper is to consider secular changes in growth, focusing initially on adult height, and extending to child height, weight, birth weight and growth tempo. Tempo is the rate at which a child's skeleton matures, indicated by the timing of puberty and the age of peak height velocity (Tanner, 1962). This rate is difficult to estimate on an epidemiological scale, but the age of menarche in girls, which is closely related to it, is easy to measure and has been recorded almost as extensively as height.

Thus, the focus is on secular changes in height, weight and age of menarche in countries of the Western world over the last two centuries. The Third World, which has provided the most dramatic examples of secular trend in recent years, is considered relatively briefly so as to keep the subject manageable. Also it is important to emphasize that these Third World trends are mirrors of what occurred in Europe in earlier years. Indeed the whole area of secular height change in Europe and North America during the last four centuries has recently spawned its own specialty of 
anthropometric history (Floud et al. 1990; Fogel, 1993; Komlos, 1994).

While documenting the scale of the secular trend, a further aim of the present paper is to discuss causation; why does it happen? The simple answer is implicit in Tanner's (1992) phrase, 'growth is a mirror of the conditions of society'. Secular change reflects the varying health and affluence of populations over time, and it also highlights inequalities of health and wealth within populations. However, why does the secular trend continue in some countries when it has stopped in others? To what extent is secular trend inter-generational; do parents pass their improved health and height on to their children, and if so, how? Are trends in height, weight and tempo synchronized with each other; do they increase and decrease together? If not, why not? Do the trends show sexual dimorphism? What does all this tell us about the underlying mechanisms?

The aim here is both to pose questions and to try to answer them. Although the answers are far from complete, they do highlight gaps in our knowledge that deserve further research.

\section{Measures of secular trend}

The process of reviewing secular trends in growth is inevitably selective due to the wide range of measurements, countries and time periods where trends have been documented. Previous excellent reviews should be consulted to obtain a broader perspective (Roche, 1979; Van Wieringen, 1986; Tanner, 1987; Hauspie et al. 1997).

\section{Adult height}

Information on adult height in the past comes mainly from slave and conscript data, the latter available for several European countries since the 19th century and before. In some countries minimum height criteria operated, so that short recruits were excluded, and mean height was biased upwards. However, in other countries where conscription was complete, it provides an unbiased estimate of height over time at one particular age. The most dramatic example is the Dutch series from 1851 to 1983 (Van Wieringen, 1986), where the changing height distribution of conscripts over 130 years is presented as a set of curves showing how the centile corresponding to a given height changes over time. For example, a height of $1.70 \mathrm{~m}$, on the 76 th centile in 1863 , had fallen to the 5 th centile by 1983 . A height of $1.80 \mathrm{~m}$, on the 98 th centile in 1863 , was on the 43rd centile 120 years later. After the Second World War the conscripts had become so tall that extra categories were added to the graph, the highest at $2.00 \mathrm{~m}$.

Apart from minor year-on-year fluctuations and a slight slowing in the 1890s, the overall trend was upwards throughout the period, and faster after the Second World War than before. There was still evidence of a trend in the 1980 s, and recent data confirm that it continues (Gerver et al. 1994; Fredriks et al. 1998). Table 1 gives selected height centiles by age and sex from the last three Dutch national growth surveys between 1965 and 1997, showing a $20 \mathrm{~mm}$ increase in median male adult height between 1980 and 1997, and $26 \mathrm{~mm}$ at the 97 th centile. The corresponding increases for females are larger.

The slowing in height at the end of the last century was more marked in Italian conscripts (Hermanussen et al. 1995). Fig. 1 shows that between 1896 and 1900 mean height fell by $19 \mathrm{~mm}$, more than cancelling out the increase seen in the previous 35 years. Apart from this disturbance, the overall impression from Fig. 1 is the consistent and increasing trend in height of Italian conscripts throughout the period 1854-1963.

Recent data for 18-year-old conscripts demonstrate rising trends in height between 1960 and 1990 in eleven European countries (Schmidt et al. 1995). The Dutch are the tallest $(1.81 \mathrm{~m}$ in 1990$)$ and the Portuguese the shortest $(1.70 \mathrm{~m})$. The trends tend to be greater in the shorter groups, e.g. $24 \mathrm{~mm} /$ decade in Spain v. $9 \mathrm{~mm} /$ decade in Norway, and the taller North European groups show some evidence of slowing during the period. Based on population surveys, rates of up to $10 \mathrm{~mm} /$ decade are typical for Western European countries in recent years, while Eastern Europe and Japan have achieved $30 \mathrm{~mm} /$ decade (Hauspie et al. 1997).

Apart from conscripts there is a dearth of long-term information on adult height, particularly for women. Kuh et al. (1991) assembled data for cohort members and their parents from the 1946 and 1958 British cohort studies to obtain values of adult height by sex and year of birth from 1892 to 1958 . For men the mean trend over the period was $10.9 \mathrm{~mm} /$ decade, while for women it was $3.6 \mathrm{~mm} /$ decade, one-third the rate and very significantly smaller $(P<0 \cdot 001)$.

Table 1. Height centiles $(\mathrm{mm})$ by age and sex from three Dutch national growth surveys (from Fredriks et al. 1998)

\begin{tabular}{|c|c|c|c|c|c|c|c|c|c|}
\hline \multirow[b]{2}{*}{ Age (years) } & \multirow[b]{2}{*}{ Year } & \multicolumn{3}{|c|}{ Boys } & \multicolumn{3}{|c|}{ Girls } & \multicolumn{2}{|c|}{$\mathrm{SD}$} \\
\hline & & $3 r d$ & 50th & 97th & $3 r d$ & 50th & 97th & Boys & Girls \\
\hline \multirow[t]{3}{*}{1} & 1965 & 719 & 770 & 818 & 709 & 756 & 805 & 26 & 26 \\
\hline & 1980 & 714 & 764 & 814 & 697 & 748 & 799 & 26 & 26 \\
\hline & 1997 & 714 & 766 & 817 & 701 & 766 & 801 & 28 & 26 \\
\hline \multirow[t]{2}{*}{8} & 1965 & 1188 & 1296 & 1403 & 1188 & 1290 & 1393 & 57 & 56 \\
\hline & 1997 & 1219 & 1328 & 1438 & 1207 & 1315 & 1423 & 58 & 58 \\
\hline \multirow[t]{3}{*}{21} & 1965 & 1640 & 1780 & 1901 & 1543 & 1663 & 1779 & 68 & 62 \\
\hline & 1980 & 1693 & 1820 & 1946 & 1568 & 1683 & 1800 & 67 & 62 \\
\hline & 1997 & 1707 & 1840 & 1972 & 1584 & 1706 & 1828 & 71 & 65 \\
\hline
\end{tabular}




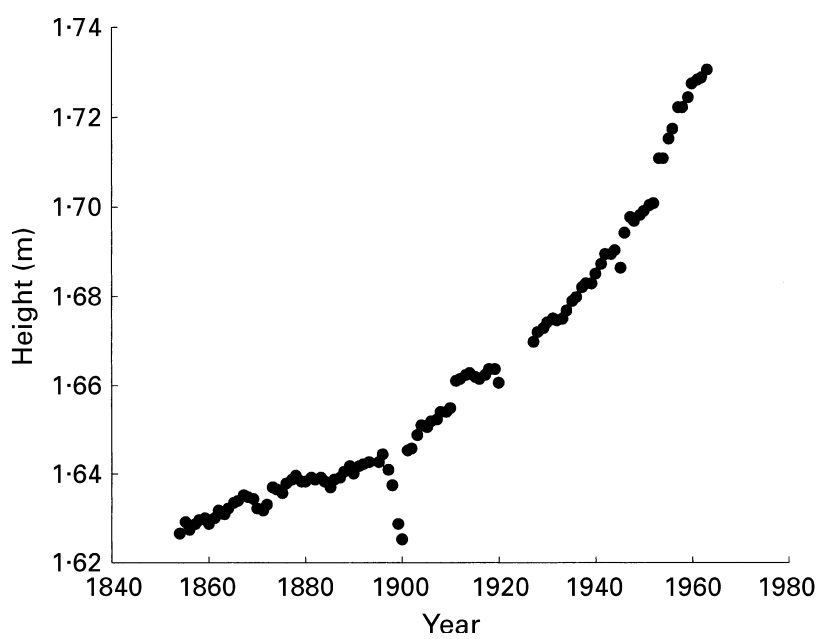

Fig. 1. Mean height in Italian conscripts from 1854 to 1963. (From Hermanussen et al. 1995)

This sexual dimorphism in the height trend is striking, and has not been observed elsewhere. It was greater before 1940 than after, and was still present when expressed in percentage terms. Among parents born before 1905 fathers were $6.9 \%$ taller than mothers, whereas in the 1958 cohort men were $9.3 \%$ taller than women.

Kuh et al. (1991) point out that, in general, growth in boys is believed to be more responsive (or plastic) than in girls to changes in the environment, so that in good times boys grow relatively faster, but when times get hard their growth is more affected. Eveleth \& Tanner (1990) in their discussion of environmental influences on growth make the same point. However, Kuh et al. (1991) find the evidence for male plasticity unconvincing, and look for other explanations.

Whatever the causation, the sexual dimorphism in height trend highlights an interesting contradiction. Francis Galton (1886) in his famous paper on regression to the mean in hereditary stature assumed an $8 \%$ sex difference in height when he adjusted for sex differences in the heights of the family offspring, and the same value of $8 \%$ is seen in many populations today (Cole, 2000). However Cole (2000), like Kuh et al. (1991), found that the percentage difference increased with time. Thus, men have either remained consistently $8 \%$ taller than women over the last 110 years, or they have been getting progressively taller. The two observations are incompatible.

The simplest explanation is to do with the families that Galton (1886) studied. If they were relatively advantaged (as they presumably were), the percentage difference in parental heights could have been greater than that for the general population at that time, which would bring it nearer to the current value of $8 \%$.

\section{Child height}

The size of the secular height trend in childhood varies with the age of the child. Dutch infants at 1 year of age were consistently shorter in 1997 than they were in 1965 (Table 1), while at ages 8 and 21 years they were appreciably taller. Takaishi (1995) published height data from birth to 17 years

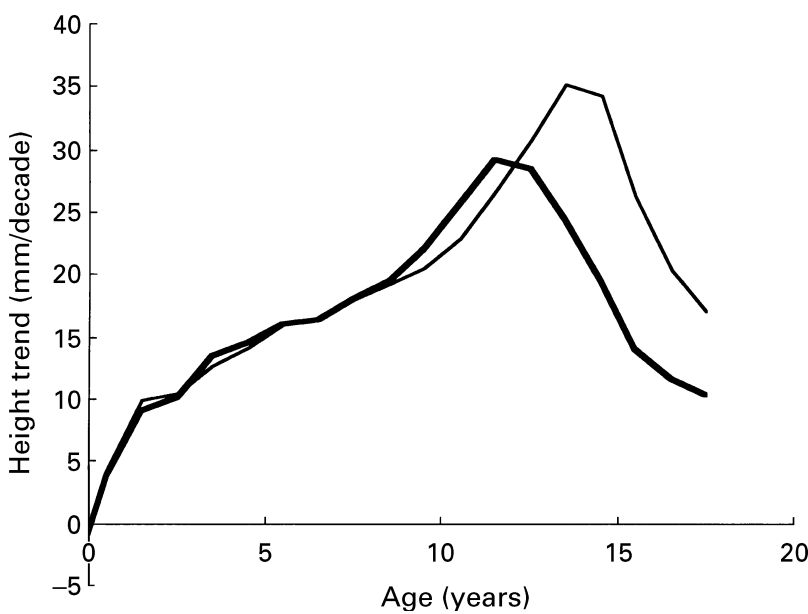

Fig. 2. Secular trends in height by sex for Japanese children between 1950 and 1990. (®), Boys; $(\multimap)$, girls. (From Takaishi, 1995)

for Japanese children between 1940 and 1990, during which time there has been a dramatic increase in height at most ages. Fig. 2 plots the secular trend between 1950 and 1990 by age and sex, showing little effect before 2 years, like the Dutch pattern in Table 1. Subsequently the trend increases to a peak at age 11 years in girls and 14 years in boys, and then falls back to a value in adulthood similar to that seen at age 2 years, at least in girls. The boys' curve is still falling at age 17 years, and probably returns to the age 2 years level by age 20 years.

Thus the secular trend in childhood can be viewed in three distinct periods: before age 2 years, where there is very little trend; from age 2 years to puberty, where the increasing trend is clearly related to the pubertal growth spurt; post-puberty where the trend falls to match that for adults. The dramatic increase in trend at puberty is due to an increased growth tempo, with children growing faster and maturing earlier, and this transiently magnifies the trend at the age of peak height velocity. However, after it has passed, Fig. 2 shows that the increase in final height $(\mathrm{mm})$ has already been achieved by the age of 2 years.

To try to understand the basis of the secular trend, two processes need to be distinguished: trends in size in early life up to age 2 years, which are carried through to adulthood, and trends in maturation, as exemplified by the age of menarche.

\section{Weight}

Along with secular changes in height there are also concomitant changes in weight, both in adults and in children. As an example, changes since 1920 in height and weight of 8-18-year-old Oslo schoolgirls show clear upward trends over the period, steeper before the Second World War than after, and with a sharp downturn during wartime which was most marked at age 12 years (Liestøl \& Rosenberg, 1995). Although height has largely stabilized since 1975, weight has continued to increase, reflecting the growing epidemic of obesity throughout the Western world. Obesity is often documented using the BMI (weight/height ${ }^{2}$ ) rather than weight. The increase in obesity has been most 
marked in North America (Troiano et al. 1995), but has also affected countries throughout Europe, e.g. Denmark (Sørensen \& Price, 1990). The timing and pattern of the obesity epidemic has been quite different from the secular trend in height, and this difference reflects its different aetiology.

\section{Birth weight}

Table 1 and Fig. 2 have already shown that the secular trend in height is not apparent before the age of 2 years. This finding suggests that size at birth, most simply measured by birth weight, has also not shown a secular trend. In fact, there is evidence that during the second half of the 19th century, when height was rising steadily in several Western countries, birth weight was actually falling. In Norway, where birth weight was routinely monitored in three cities between 1860 and 1984 (Rosenberg, 1988), mean birth weight in married women fell slightly from 1860 to 1900 , rose between 1900 and 1940 by about $150 \mathrm{~g}$ and then levelled off again. Similarly, Ward \& Ward (1984) found that mean birth weight in Montreal, Canada, fell by $400 \mathrm{~g}$ between 1850 and 1900 .

Recently, birth weight has changed little in Norway, but there are signs that birth weight is rising in North America (Alberman, 1991), probably due to increasing levels of maternal obesity. This finding highlights the differences in timing of the secular changes in body size at birth and at 2 years.

\section{Sitting height and leg length}

It is well known that the pubertal growth spurt occurs first in the long bones, i.e. the arms and legs (Tanner, 1962), with the trunkal spurt following some time later. A related phenomenon has been seen in Japanese children, who underwent a dramatic spurt in height between 1950 and 1990 (Fig. 2). Nearly all the trend was explained by an increase in leg length, which is the most rapidly growing part of the body in early childhood, as opposed to sitting height which changed little (Tanner et al. 1982). As the authors said, 'Our results ... make it clear that the secular trend in adult measurements, both in men and women, is chiefly or wholly a trend in length of legs'.

\section{Tempo of growth}

The timing of menarche in girls provides a convenient proxy for the rate of maturation and the tempo of growth. The age of menarche has fallen sharply since the 19th century, e.g. in Norway (Liestøl, 1982) and Denmark (Helm \& Helm, 1987), at a rate of up to 12 months per decade. However, in recent years the trend has halted, and in many cases reversed, the low point of menarche at 13 years or thereabouts being reached for girls born during the Second World War in Belgium (Wellens et al. 1990), approximately 1946 in England (Roberts, 1994), between 1953 and 1970 in Denmark (Helm \& Grølund, 1998) and approximately 1965 in Poland (Hulanicka, 1991). In Belgium between 1919 and 1967 the 90th centile of menarcheal age fell faster than the median, while the 10th centile hardly changed, showing that late menarche has become progressively less common over the period (Hauspie et al. 1997). Thus, over the last 30 years the age of menarche has not changed, yet the secular trend in height has continued. Hulanicka (1991) felt that the turnabout in the age of menarche was due to falling living standards in Poland after 1978, but it may instead be part of a more general pattern of stabilizing menarcheal age throughout Europe since the Second World War.

\section{Comparison of trends}

The secular trends to increasing height and earlier menarcheal age have been seen over the last 150 years or more, interspersed with shorter periods of cessation or reverse trend during times of war or privation. In general the height trend has eased but not stopped, whereas the menarcheal trend has stopped and even reversed. Birth weight has fallen, remained static or risen at times unrelated to the timing of the height and menarche trends. The lack of synchrony in the height, birth weight and menarche trends suggests that their underlying causal mechanisms differ.

\section{Factors affecting secular change}

\section{Poverty and affluence}

So what causes the secular change in body size and growth tempo? Poor growth is known to be closely associated with poverty and deprivation, hence the phrase of Tanner (1992) linking growth to the conditions of society. There is abundant evidence that the secular trend in height is affected by socio-economic factors such as social class (Kuh et al. 1991), income and education (Meyer \& Selmer, 1999), family size (Chinn et al. 1989), urban v. rural location (Weber et al. 1995) and region (Padez \& Johnston, 1999). Similar factors affect the menarcheal trend (LaskaMierzejewska et al. 1982; Bielicki et al. 1986; Rimpelä \& Rimpelä, 1993; Roberts, 1994). It is also known that growth is affected by poor housing and overcrowding (Foster et al. 1983). These factors all more or less directly affect the health of the growing child through their environmental wealth and/or hygiene.

\section{Height factors}

So the secular changes in height and menarche are driven by underlying changes in health and affluence. This observation is hardly new, and has been understood for almost 200 years (Tanner, 1981). However, precisely how and when living conditions affect secular growth change has not been considered to the same extent, in terms of the susceptible growth period and the underlying physiology.

We have already seen that secular changes in adult height have their genesis in the first 2 years of life, most probably through increased leg length (for example, see Fig. 2). This period is when postnatal growth is at its most rapid, and hence is most susceptible to adverse conditions. In the developing world poor growth in infancy leads to reduced height-for-age or stunting, and it is known to be concentrated in the first 1-2 years of life. By viewing the secular trend in height as a reduction in the degree of stunting, it 
should be possible to extrapolate from the mechanisms known to affect stunting to those causing secular height changes.

A recent workshop on the causes and mechanisms of linear growth retardation identified three causes of stunting: nutrition; infection; the mother-infant interaction (Waterlow, 1994). Genetics was thought to be relatively unimportant because affluent children in developing countries grow as well as those in the developed world. In terms of the secular trend, succeeding generations come from the same gene pool by definition, and the time scale involved is too short for the gene pool to change appreciably. So genetics is equally unlikely to be important for the secular trend.

Nutrition is clearly a critical factor, but the most obvious nutrient, energy intake, is unlikely to be limiting, as stunting is not usually associated with wasting, i.e. energy intake is sufficient to maintain the child's weight in proportion to their height. Thus, quality rather than quantity of the diet is what counts, with animal protein, fat, micronutrients, vitamins, essential fatty acids and amino acids all being proposed as relevant (Allen \& Uauy, 1994). To support this idea Takahashi (1984) has linked the secular trend in height in Japan to the consumption of milk, which has risen steeply since the Second World War.

Infection is important in the way that it interacts with nutrition. Infection leads to gastrointestinal damage and hence malabsorption, particularly of micronutrients, and allows increased access to antigens and bacteria. Systemically, infection leads to further nutrient loss (Waterlow, 1994). Better nutrition can compensate for the deleterious effects of infection by providing a buffer of the nutrients that are at risk.

Appetite is another important aspect of the child's nutrition, which depends on the make-up of the diet, the child's health (infection reduces appetite), and also the attention paid to the child during feeding.

The attention paid to the child relates to the third important factor, the mother-child interaction. In broad terms the mother's involvement with the child is in three parts: pregnancy; lactation; childcare. The quality of the pregnancy relates to the child's weight and length at birth, and for 'at risk' women pregnancy supplementation increases birth weight (Ceesay et al. 1997).

Birth weight is a strong predictor of adult height. Table 2 summarizes factors affecting height at 36 years in the British 1946 cohort (Kuh \& Wadsworth, 1989), arranged in

Table 2. Factors affecting height $(\mathrm{mm})$ at 36 years in the British 1946 cohort, based on 1667 cases (from Kuh \& Wadsworth, 1989)

\begin{tabular}{lcc}
\hline Variable & Regression coefficient & F ratio \\
\hline Male sex & 129 & 2506 \\
Midparental height $(\mathrm{mm})$ & 0.54 & 526 \\
Birth weight $(\mathrm{kg})$ & 23 & 76 \\
Birth order & $-8 \cdot 2$ & 23 \\
Father's social class & $-4 \cdot 2$ & 11 \\
Younger siblings & -6.3 & $7 \cdot 4$ \\
Overcrowding & $-8 \cdot 4$ & $7 \cdot 0$ \\
Father's education & $3 \cdot 4$ & $5 \cdot 7$ \\
Mother's education & $6 \cdot 2$ & 4.4 \\
\hline
\end{tabular}

descending order of significance, with birth weight just behind midparental height and ahead of several social factors. A $1 \mathrm{~kg}$ increment in birth weight corresponds to an increment of $23 \mathrm{~mm}$ in adult height, as against an increment of $54 \mathrm{~mm}$ for a $100 \mathrm{~mm}$ increment in midparental height; i.e., 1SD increments in birth weight and midparental height correspond to increments of $11 \mathrm{~mm}$ and $27 \mathrm{~mm}$ respectively in adult height.

Thus, the mother contributes to her offspring's adult height in two distinct ways, through her own height (via midparental height) and through the size of the baby that she grows. However, recently other contributory maternal factors have been identified with data from the 1958 British cohort at 33 years (Hennessy \& Alberman, 1998), as summarized in Table 3. The most important is the mother's birth weight adjusted for gestation, which is more predictive than her unadjusted birth weight. Thus, maternal fetal growth rate predicts the infant's fetal growth rate, as hypothesized by Ounsted et al. (1986). Smoking in pregnancy is a known risk factor for low birth weight, and maternal weight-for-height is known to be related to birth weight, but the effect of early menarche on birth weight is not so well-known.

Over and above the maternal contribution, earlier work using data from the 1958 cohort to age 23 years (Emanuel et al. 1992) identified a small positive effect of grandmother's height on grandchild's birth weight, but this effect was no longer apparent in the more recent analyses (Hennessy \& Alberman, 1998).

Thus, birth weight is affected by maternal birth weight, maternal height and maternal weight, and possibly grandmaternal factors as well, allowing successive generations to influence the size of their offspring at birth. An increase in any of these factors in one generation will lead to larger babies in the next generation, who will produce larger babies in their turn. In theory, the process should ripple through successive generations, getting weaker with passing time, and this is precisely how the secular trend appears.

Yet curiously this process does not explain the secular trend in height, as trends in birth weight over time have been unrelated to the corresponding height trends. While adult height has increased, early body size has remained broadly the same. This trend is clear from Table 1, where length at 1 year in successive Dutch national growth surveys has not changed despite strong trends at older ages. This lack of change is counter-intuitive, since if height has increased due to better growth conditions, early size should

Table 3. Factors affecting birth weight for gestation ( $\mathrm{g}$ ) in the children of women from the British 1958 cohort, based on 2578 cases (from Hennessy \& Alberman, 1998)

\begin{tabular}{lcc}
\hline Variable & $\begin{array}{c}\text { Regression } \\
\text { coefficient }\end{array}$ & $95 \% \mathrm{Cl}$ \\
\hline Maternal birth weight SDS & 100 & 83,117 \\
Maternal pregnancy smoking & -199 & $-236,-161$ \\
Male sex & 106 & 74,137 \\
Maternal height SDS & 57 & 40,74 \\
Maternal weight-for-height SDS & 54 & 37,70 \\
Menarche before 12 years & 78 & 37,119 \\
\hline
\end{tabular}

SDS, standard deviation score. 
have been affected as well. This factor is considered further later.

The mother's second link to the child is through lactation. In the developing world stunting starts to develop only after 4 months of life, suggesting that early lactation protects the infant from the environment both through the nutrients and the protective factors that breast milk provides. After 6 months breast milk alone is insufficient for the infant's needs, and it may be that improved maternal conditions lead to more breast milk and hence faster growth in the baby. Yet lactation supplement trials have had minimal impact on growth (Prentice et al. 1986), and in any case the proportion of mothers in the developed world who breast-feed beyond 6 months has been relatively low for much of the 20th century, since the advent of artificial feeding. This factor is unlikely to make a major contribution to the secular trend.

The third maternal contribution to the child, beyond pregnancy and lactation, is their care. The amount of care that a mother invests in her child involves balancing her resources, i.e. her social and financial standing, with the demands that are made on her, i.e. the size of her family. The beneficial effect on growth of greater affluence has already been discussed, but less so the cost of increased family size. The factors affecting adult height in Table 2 illustrate this distinction well. The mother's resources are represented by her size (height and child's birth weight), which affect her child positively, while birth order and the number of younger siblings, which together define the size of the family, are potent negative factors. Parental education, social class and overcrowding are further proxies for the family's resources.

Although this contribution explains the relevance of the factors in Table 2, it does not further the quest to identify the physiological basis for the secular height trend. With increasing affluence mothers are able to invest more (both financially and emotionally) in their child, and in detail this effect cannot be separated from other factors that are related to affluence. How does affluence improve growth? This question brings us full circle, to better nutrition and less infection.

In the search for causes of stunting, there is now increasing interest in the effect of growth hormone $(\mathrm{GH})$ in early life. Karlberg's (1989) ICP (infant-child-puberty) model reflects the belief that $\mathrm{GH}$ starts to be active at 9 months or so, perhaps when $\mathrm{GH}$ receptors are first expressed (Waterlow, 1994). These GH receptors are believed to act on the growth plates of the long bones, so that factors which delay the expression of the GH receptors could lead to stunting through their effect on long-bone growth. At this stage nutrition may play a role in affecting $\mathrm{GH}$ receptor expression, although the precise mix of nutrients involved in the process has yet to be identified.

There is one remaining question: how does maternal nutritional status affect later growth without necessarily altering birth weight? Considerable length centile crossing takes place in the first 2 years, demonstrating the lack of correlation between birth size and later length gain. The latter rate is determined early in life, probably early in pregnancy, and reflects the size of both parents, whereas birth weight is influenced only by the mother. It is likely that actual as opposed to genetic parental size is what sets the child's growth rate.

This possibility is consistent with the hypothesis that the scale and timing of $\mathrm{GH}$ receptor expression is predetermined during pregnancy and, thus, is affected both by genetics and by the environment of the uterus, but that the actual process of expression, which occurs 1 year later, is the interaction between this programmed state and the child's environment. Thus, the outcome will depend on genetic, inter-generational and environmental factors, all of which are known to relate to the secular trend.

\section{Menarcheal factors}

The secular trend in menarcheal age is strikingly different from the secular trend in height; in Northern and Eastern Europe the trend has more or less stopped yet height continues to increase. This finding suggests that there is a physiological lower limit to the mean age of menarche, averaging about 13 years, and the effect of poor environmental conditions is to delay menarche beyond this age. Thus, what are the factors that cause the delay?

Before trying to answer this question, it is worth asking why there should be a secular trend in menarcheal age at all. What is the benefit in menarcheal age being delayed when environmental conditions are poor? Menarche occurs about 1 year after the age of peak height velocity (Tanner, 1962), which ensures that girls are close to final height before they become fertile. If there were no secular trend in sexual maturation, e.g. menarche occurred at 13 years irrespective of the growth rate to that point, girls growing in adverse conditions would end up even shorter as adults than they actually were. The rate of maturation determines the time scale over which adult height is attained, so in adverse conditions where growth is slow, it may be that an extended growth period protects final height.

Of the factors known to affect menarcheal timing, genetics via maternal tempo is the most obvious; menarche is early in girls whose mothers had an early menarche (Moisan et al. 1990). Yet as already discussed this factor does not explain the secular trend; the gene pool has not had sufficient time to respond. Two other factors have been identified that affect menarche. The first is the child's size in childhood. An analysis of 4000 Oslo schoolgirls (Liestøl \& Rosenberg, 1995) relating menarcheal status to age, height and weight by logistic regression showed that weight was positive and highly significant $(t>10 ; P<0.001)$, whereas height was completely non-significant. Power et al. (1997) showed that BMI at age 7 years was highly predictive of later menarcheal age. This finding appears to imply a causal relationship between child weight and menarche, the 'critical weight hypothesis' proposed by Frisch \& Revelle (1970). However, Ellison (1982) failed to find any evidence of a critical weight or fat mass at the time of menarche. He found instead that height velocity was a far stronger predictor than weight, suggesting that the timing of menarche is determined by the rate of maturation not body size. Twin studies also show that the genetic control of sexual maturation is independent of the corresponding genetic system determining body size (Loesch et al. 1995). 
The critical weight hypothesis is now generally discredited, although it is being invoked again, linked to the hormone leptin (Clayton et al. 1997).

The second factor affecting the timing of menarche operates near birth. Liestøl (1982) studied Norwegian hospital records of menarcheal age between 1860 and 1950, and related them to the national gross domestic product over the same period. In broad terms mean menarcheal age fell as gross domestic product rose, and by introducing a lag between the two time series he maximized the correlation between them by relating menarcheal age to gross domestic product at the time of the women's birth. He interpreted this relationship as meaning that environmental factors affecting the timing of menarche operate near birth, not later. This theory refutes the idea that weight during childhood influences menarche, for if it did, factors that affected child weight would also affect menarche. However, these factors would act in childhood not at birth, which is inconsistent with the birth factor being more important than later factors.

Another argument against child weight being a causal factor is the recent rise in obesity. It has led to an appreciable increase in weight before puberty, yet the age of menarche has not changed during this time. The conclusion must be that menarche is determined by a factor or factors that set the rate of maturation and operate around birth (preand/or postnatally), and these same factors also determine subsequent weight gain. Thus, weight and menarche are related, but not causally.

Further evidence supporting an early life influence on maturation was provided by Cole \& Cole (1992) who showed that bone age in children from Middlesbrough, Cleveland was delayed by up to 4 months in the most deprived areas. The effect was unrelated to age, leading the authors to conclude that the bone age deficit could be caused by deprivation retarding skeletal maturation during a critical period in early life.'

What these factors are that delay maturation is something of a mystery, as they are unrelated to birth weight and to child height. This needs further work.

\section{Conclusions}

The secular trend to increasing height continues across Europe, while that for menarcheal age, which has fallen steeply in the past, is now stable at approximately 13 years in many European countries. The two trends combine in childhood to give a transiently steeper height trend than in adulthood, but no trends are apparent before the age of 2 years. The adult trend is similar to that at age 2 years, so the increment in adult height is achieved by the age of 2 years. This early increase in height gain can be thought of as a reduction in stunting, and stunting is known to be related to lower leg growth and influenced by concurrent nutrition. It is suggested that growth at this time is the outcome of an interaction between concurrent nutrition and the growth rate set during pregnancy, reflecting parental size. The timing of menarche is probably also set near the time of birth, but the mechanisms involved are unclear.

\section{Acknowledgements}

I thank Chris Power for useful discussions, and Michael Hermanussen for providing me with his Italian conscript data.

\section{References}

Alberman E (1991) Are our babies becoming bigger? Journal of the Royal Society of Medicine 84, 257-260.

Allen LH \& Uauy R (1994) Guidelines for the study of mechanisms involved in the prevention or reversal of linear growth retardation in developing countries. European Journal of Clinical Nutrition 48, Suppl. 1, S212-216.

Bielicki T, Waliszko Q, Hulanicka B \& Kotlarz K (1986) Socialclass gradients in menarcheal age in Poland. Annals of Human Biology 13, 1-11.

Bogin B \& Keep R (1999) Eight thousand years of economic and political history in Latin America revealed by anthropometry. Annals of Human Biology 26, 333-351.

Ceesay SM, Prentice AM, Cole TJ, Foord F, Weaver LT, Poskitt EME \& Whitehead RG (1997) Effects on birthweight and perinatal mortality of maternal dietary supplements in rural Gambia: 5 year randomised controlled trial. British Medical Journal 315, 786-790.

Chinn S, Rona RJ \& Price CE (1989) The secular trend in height of primary school children in England and Scotland 1972-79 and 1979-86. Annals of Human Biology 16, 387-395.

Clayton PE, Gill MS, Hall CM, Tillmann V, Whatmore AJ \& Price DA (1997) Serum leptin through childhood and adolescence. Clinical Endocrinology 46, 727-733.

Cole TJ (2000) Galton's midparent height revisited. Annals of Human Biology 27, (In the Press).

Cole TJ \& Cole AJL (1992) Bone age, social deprivation, and single parent families. Archives of Disease in Childhood 67, 1281-1285.

Ellison PT (1982) Skeletal growth, fatness and menarcheal age: a comparison of two hypotheses. Human Biology 54, 269-281.

Emanuel I, Filakti H, Alberman E \& Evans SJW (1992) Intergenerational studies of human birthweight from the 1958 birth cohort. 1. Evidence for a multigenerational effect. British Journal of Obstetrics and Gynaecology 99, 67-74.

Eveleth PB \& Tanner JM (1990)Worldwide Variation in Human Growth. Cambridge: Cambridge University Press.

Floud R, Wachter K \& Gregory A (1990) Height, Health and History. Cambridge: Cambridge University Press.

Fogel RW (1993) New sources and new techniques for the study of secular trends in nutritional status, health, mortality, and the process of aging. Historical Methods 26, 5-43.

Foster JM, Chinn S \& Rona RJ (1983) The relation of the height of primary school children to population density. International Journal of Epidemiology 12, 199-204.

Fredriks AM, van Buuren S, Burgmeijer RJF, Verloove-Vanhorik SP \& Wit JM (1998) Nederlandse groeidiagrammen 1997 in historisch perspectief (The Dutch growth diagrams 1997 in historical perspective). In De vierde Landelijke Groeistudie (1997) Presentatie nieuwe groeidiagrammen (The Fourth Nationwide Growth Survey (1997)), pp. 1-13 [JM Wit, editor]. Leiden, The Netherlands: TNO Preventie en Gezondheid.

Frisch RE \& Revelle R (1970) Height and weight at menarche and a hypothesis of critical body weights and adolescent events. Science 169, 397-399.

Galton F (1886) Regression towards mediocrity in hereditary stature. Journal of the Anthropological Institute of Great Britain and Ireland 15, 246-263. 
Gerver WJ, De Bruin R \& Drayer NM (1994) A persisting secular trend for body measurements in Dutch children. The Oosterwolde II Study. Acta Paediatrica 83, 812-814.

Hauspie RC, Vercauteren M \& Susanne C (1997) Secular changes in growth and maturation: an update. Acta Paediatrica Suppl. 423, 20-27.

Helm P \& Grølund L (1998) A halt in the secular trend towards earlier menarche in Denmark. Acta Obstetricia et Gynecologica Scandinavica 77, 198-200.

Helm P \& Helm S (1987) Uncertainties in designation of age at menarche in the nineteenth century, revised mean for Denmark, 1835. Annals of Human Biology 14, 371-374.

Hennessy E \& Alberman E (1998) Intergenerational influences affecting birth outcome. I Birthweight for gestational age in the children of the 1958 British Birth Cohort. Paediatric and Perinatal Epidemiology 12, Suppl. 1, 45-60.

Hermanussen M, Burmeister J \& Burkhardt V (1995) Stature and stature distribution in recent West German and historic samples of Italian and Dutch conscripts. American Journal of Human Biology 7, 507-515.

Hulanicka B (1991) Deceleration of age at menarche in Poland. Annals of Human Biology 18, 507-513.

Karlberg J (1989) A biologically oriented mathematical model (ICP) for human growth. Acta Paediatrica Scandinavica Suppl. 350, 70-94.

Komlos J (editor) (1994) Stature, Living Standards, and Economic Development. Chicago, IL: University of Chicago Press.

Kuh DL, Power C \& Rodgers B (1991) Secular trends in social class and sex differences in adult height. International Journal of Epidemiology 20, 1001-1009.

Kuh DL \& Wadsworth M (1989) Parental height: childhood environment and subsequent adult height in a national birth cohort. International Journal of Epidemiology 18, 663-668.

Laska-Mierzejewska T, Milicer H \& Piechaczek H (1982) Age at menarche and its secular trend in urban and rural girls in Poland. Annals of Human Biology 9, 227-233.

Liestøl K (1982) Social conditions and menarcheal age: the importance of early years of life. Annals of Human Biology 9, 521-537.

Liestøl K \& Rosenberg M (1995) Height, weight and menarcheal age of schoolgirls in Oslo - an update. Annals of Human Biology 22, 199-205.

Loesch DZ, Huggins R, Rogucka E, Hoang NH \& Hopper JL (1995) Genetic correlates of menarcheal age: a multivariate twin study. Annals of Human Biology 22, 479-490.

Meyer HE \& Selmer R (1999) Income, educational level and body height. Annals of Human Biology 26, 219-227.

Moisan J, Meyer F \& Gingras S (1990) A nested case-control study of the correlates of early menarche. American Journal of Epidemiology 132, 953-961.

Ounsted M, Scott A \& Ounsted C (1986) Transmission through the female line of a mechanism constraining human fetal growth. Annals of Human Biology 13, 143-151.

Padez C \& Johnston F (1999) Secular trends in male adult height 1904-1996 in relation to place of residence and parent's educational level in Portugal. Annals of Human Biology 26, 287-298.

Power C, Lake JK \& Cole TJ (1997) Body mass index and height from childhood to adulthood in the 1958 British born cohort. American Journal of Clinical Nutrition 66, 1094-1101.

Prentice AM, Whitehead RG, Prentice A \& Cole TJ (1986) Interventions to improve lactational performance: a practical proposition? In Proceedings of XIII International Congress of Nutrition, Brighton, pp. 619-621 [TG Taylor and NK Jenkins, editors]. London: John Libbey \& Co. Ltd.
Rimpelä AH \& Rimpelä MK (1993) Towards an equal distribution of health? Socioeconomic and regional differences of the secular trend of the age of menarche in Finland from 1979 to 1989. Acta Paediatrica 82, 87-90.

Roberts DF (1994) Secular trends in growth and maturation in British girls. American Journal of Human Biology 6, 13-18.

Roche AF (1979) Secular trends in human growth, maturation, and development. Monographs of the Society for Research in Child Development 44, 1-120.

Rosenberg M (1988) Birth weights in three Norwegian cities, 1860-1984. Secular trends and influencing factors. Annals of Human Biology 15, 275-288.

Schmidt IM, Jørgensen MH \& Michaelsen KF (1995) Height of conscripts in Europe: is postneonatal mortality a predictor? Annals of Human Biology 22, 57-67.

Sørensen TI \& Price RA (1990) Secular trends in body mass index among Danish young men. International Journal of Obesity 14, 411-419.

Takahashi E (1984) Secular trend in milk consumption and growth in Japan. Human Biology 56, 427-437.

Takaishi M (1995) Growth standards for Japanese children - an overview with special reference to secular change in growth. In Essays on Auxology Presented to James Mourilyan Tanner by Former Colleagues and Fellows, pp. 302-311 [R Hauspie, G Lindgren and F Falkner, editors]. Welwyn Garden City, Herts.: Castlemead Publications.

Tanner JM (1962) Growth at Adolescence. Oxford: Blackwell.

Tanner JM (1981) A History of the Study of Human Growth. Cambridge: Cambridge University Press.

Tanner JM (1987) Growth as a mirror of the condition of society: secular trends and class distinctions. Acta Paediatrica Japonica 29, 96-103.

Tanner JM (1992) Growth as a measure of the nutritional and hygienic status of a population. Hormone Research 38, Suppl. 1, $106-115$.

Tanner JM, Hayashi T, Preece MA \& Cameron N (1982) Increase in length of leg relative to trunk in Japanese children and adults from 1957 to 1977: comparison with British and with Japanese Americans. Annals of Human Biology 9, 411-423.

Troiano RP, Flegal KM, Kuczmarski RJ, Campbell SM \& Johnson CL (1995) Overweight prevalence and trends for children and adolescents. The National Health and Nutrition Examination Surveys, 1963 to 1991. Archives of Pediatric and Adolescent Medicine 149, 1085-1091.

Van Wieringen JC (1986) Secular growth changes. In Human Growth: A Comprehensive Treatise, vol. 3, pp. 307-331 [F Falkner and JM Tanner, editors]. New York: Plenum Press.

Ward WP \& Ward PC (1984) Infant birth weight and nutrition in industrializing Montreal. American Historical Review 89, 324-345.

Waterlow JC (1994) Summary of causes and mechanisms of linear growth retardation. European Journal of Clinical Nutrition 48, Suppl. 1, S210.

Weber G, Seidler H, Wilfing H \& Hauser G (1995) Secular change in height in Austria: an effect of population stratification? Annals of Human Biology 22, 277-288.

Weber GW, Prossinger H \& Seidler H (1998) Height depends on month of birth. Nature 391, 754-755.

Wellens R, Malina RM, Beunen G \& Lefevre J (1990) Age at menarche in Flemish girls: current status and secular change in the 20th century. Annals of Human Biology 17, 145-152. 